\title{
NREL Highlights
NREL Develops Simulations for Wind Plant Power and Turbine Loads
}

\author{
NREL researchers are the first to use a high-performance com- \\ puting tool for a large-eddy simulation of an entire wind plant.
}

Researchers at the National Renewable Energy Laboratory's (NREL) National Wind Technology Center (NWTC) successfully simulated the first aerodynamic interactions within an existing wind plant, augmenting previous studies of wind plant subsets.

Wind turbines extract energy from the wind's flow, and as a byproduct they create a wake that trails behind them. If wind turbines are arranged in an array, wakes from upwind turbines interact with downstream turbines. Wake effects include decreased power produced by downstream turbines relative to upstream turbines, as well as increased mechanical loading due to wake turbulence. The current state of knowledge concerning wind turbine wakes and how they interact with other turbines and the atmospheric boundary layer is incomplete.

Coupling atmospheric wind and turbine models, NWTC researchers were able to simulate the complex flow characteristics into and within wind plants. The simulation shows up to a $60 \%$ decrease in the performance of the turbines behind the front row in this plant, and it accurately predicted the overall plant efficiency. The simulation, using processors in NREL's Red Mesa high-performance computing system, is one of the largest ever performed in the wind industry.

The aeroelastic responses of the turbines within a wind plant were studied to characterize the fatigue loading caused by the turbulence in the boundary layer and in the wake of other turbines. The downstream turbines had higher fatigue loads, indicating that the turbulent wakes generated from upstream turbines have significant impact. This effect was highly dependent on surface roughness and atmospheric stability.

NWTC's successful calculation of the effects of turbines in a working wind plant enables designers to model the impact of upwind turbines and wakes on downwind turbines to predict and maximize wind energy capture potential and lower damaging fatigue loads.

Technical Contact: Pat Moriarty, patrick.moriarty@nrel.gov

References: Churchfield, M.J.; Lee, S.; Moriarty, P.J.; Martinez, L.A.; Leonardi, S.; Vijayakumar, G.; Brasseur, J.G. (2012). "Large-Eddy Simulation of Wind-Plant Aerodynamics." NREL Report No. CP-5000-53554.

Lee, S.; Churchfield, M.; Moriarty, P.; Jonkman, J.; Michalakes, J. (2011). "Atmospheric and Wake Turbulence Impacts on Wind Turbine Fatigue Loading." NREL Report No. CP-5000-53567.

RESEARCH \& DEVELOPMENT

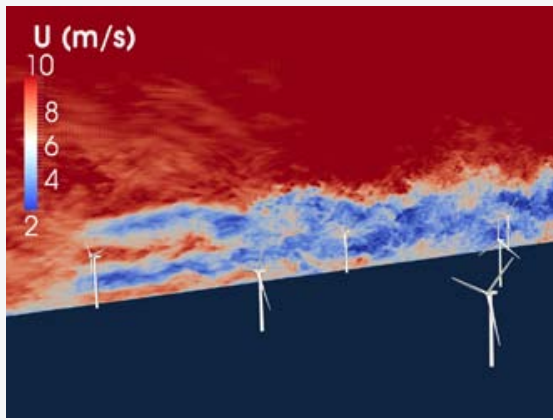

This visualization of a snapshot of instantaneous velocity clearly shows the turbulent nature of the turbine wakes. Downstream "waked" turbines produce less energy and are subject to greater fatigue loads than the upstream turbines.

\section{Key Research Results}

\section{Achievement}

NREL researchers successfully developed a methodology for performing large-eddy simulation (LES) computations of flow and aeroelastic turbine response within a modern wind plant composed of many multi-megawatt turbines.

Key Result

Researchers simulated the Lillgrund offshore facility between Denmark and Sweden and compared results with more than a year's worth of plant data. The simulated power production of the turbines in the plant agrees with field observations. Simulation of the aeroelastic response of turbines within wakes shows increased loading dependent on atmospheric conditions.

Potential Impact Improved tools for wind plant design will enable improved physical understandings of turbine interactions and ultimately lead to optimized wind plant designs with higher energy production and lower maintenance costs.

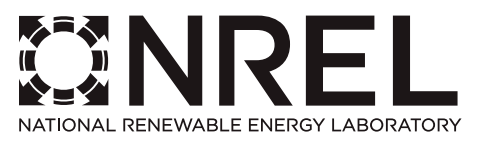

15013 Denver West Parkway | Golden, Colorado 80401 | 303-275-3000 | www.nrel.gov
NREL is a national laboratory of the U.S. Department of Energy, Office of Energy Efficiency and Renewable Energy, operated by the Alliance for Sustainable Energy, LLC.

NREL/FS-5000-54513 • April 2012 